\section{Severe folding of the inferior retina after relaxing retinectomy for proliferative vitreoretinopathy}

B Gupta, B Mokete, DAH Laidlaw and TH Williamson

\begin{abstract}
Purpose Proliferative vitreoretinopathy (PVR) is a severe complication of retinal detachment, which can be treated surgically by relaxing retinectomy. In this study, we describe patients with severe inferior retinal folding after this surgical intervention (SIRF).

detachment with PVR may be managed by pars plana vitrectomy (PPV) with relaxing retinectomy and intraocular tamponade with silicone oil. We have noticed in a small number of cases, severe folding of inferior retina (SIRF) such that it scrolls into the macular area, a complication, which has not previously been reported.
\end{abstract} Methods A retrospective review of the electronic patient records of 254 patients who received relaxing retinectomies was performed to identify patients with SIRF.

Results Five patients $(1.97 \%$ of those with retinectomy) were identified with SIRF, mean age, 51.4 years; mean follow-up, 36 months. Three patients had rhegmatogenous retinal detachment (RRD) with PVR, one had a dropped nucleus with RRD and PVR and one with giant retinal dialysis from ocular trauma. SIRF was noted from a mean $\mathbf{4 . 2}$ months after the retinectomy. All involved the macula and visions were hand movements or perception of light.

Conclusions SIRF is an uncommon but devastating complication of relaxing retinectomy with a poor visual outcome. This is the first description of this condition that we are aware of.

Eye (2008) 22, 1517-1519; doi:10.1038/eye.2008.220; published online 1 August 2008

Keywords: proliferative vitreoretinopathy; retinal detachment; retinectomy

\section{Introduction}

Proliferative vitreoretinopathy (PVR) is the most common cause of recurrent retinal detachment after retinal detachment repair occurring in $5-11 \%$ of patients ${ }^{1-3}$ and a common accompaniment to ocular trauma. Retinal

\section{Methods}

We reviewed the electronic patient records (freeware designed by Tom $\mathrm{H}$ Williamson on MS Access) of 254 patients, who had undergone a relaxing retinectomy, over a 9-year period. The surgical procedure involved diathermy to retinal blood vessels, incision of the retina, excision of the redundant anterior retina to the ora serrata, silicone oil tamponade, and laser retinopexy to the edge of the retina in three rows. In phakic patients the ends of the retinectomy were treated with cryopexy. Five patients were identified in whom the inferior retina had scrolled into the macular area (SIRF). Clinical details of these patients were obtained from an electronic patient record and by review of clinical notes. The study conformed to the Declaration of Helsinki.

\section{Results}

There were four males and one female patient, mean age 51.4 years, range $29-58$ years. Mean follow-up was 36 months. The clinical details of the patients are presented in Table 1. Three patients had RRD with macula off (1-3 months duration) with associated PVR. One patient had undergone a complicated phacoemulsification procedure with a dropped lens nucleus, which caused retinal detachment. One patient had a giant retinal dialysis with PVR from severe ocular
Department of Ophthalmology, St Thomas

Hospital, London, UK

Correspondence:

TH Williamson,

Department of

Ophthalmology,

St Thomas Hospital, Lambeth Palace Road,

London SE1 7EH, UK

Tel: + 442071887188;

Fax: +442071884312 .

E-mail: tom@

retinasurgery.co.uk

Received: 3 March 2008

Accepted in revised form:

2 June 2008

Published online: 1 August 2008

This study was based on a meeting presented on 2 November 2007 at St Andrews (BEAVRS 2007) 
Table 1 The clinical characteristics of the patients are presented

\begin{tabular}{llllllccc}
\hline Patient & Sex & $\begin{array}{c}\text { Age } \\
\text { (years) }\end{array}$ & $\begin{array}{l}\text { Presenting } \\
\text { complaint }\end{array}$ & $\begin{array}{l}\text { Presenting } \\
\text { visual acuity }\end{array}$ & $\begin{array}{l}\text { Severity of } \\
\text { PVR prior to } \\
\text { retinectomy }\end{array}$ & $\begin{array}{c}\text { Degrees of } \\
\text { relaxing } \\
\text { retinectomy }\end{array}$ & $\begin{array}{l}\text { Duration from } \\
\text { retinectomy to } \\
\text { occurrence } \\
\text { of SIRF (months) }\end{array}$ & $\begin{array}{c}\text { Final visual } \\
\text { acuity }\end{array}$ \\
\hline 1 & Male & 29 & Traumatic RRD & HM & Macular scar & $260^{\circ}$ & 5 & PL \\
2 & Male & 70 & RRD & HM & CP10 & $130^{\circ}$ & 3 & HM \\
3 & Female & 70 & $\begin{array}{l}\text { Dropped Nucleus } \\
\text { and RRD }\end{array}$ & HM & CA10 CP6 & $150^{\circ}$ & 5 & PL \\
4 & Male & 40 & RRD & HM & CA8 CP10 & $270^{\circ}$ & 6 & PL \\
5 & Male & 48 & RRD & HM & CP6 & $160^{\circ}$ & 2 & HM \\
\hline
\end{tabular}

$\mathrm{HM}=$ hand movements; $\mathrm{PL}=$ perception of light; $\mathrm{PVR}=$ proliferative vitreoretinopathy; $\mathrm{RRD}=$ rhegmatogenous retinal detachment; SIRF $=$ severe inferior retinal folding.

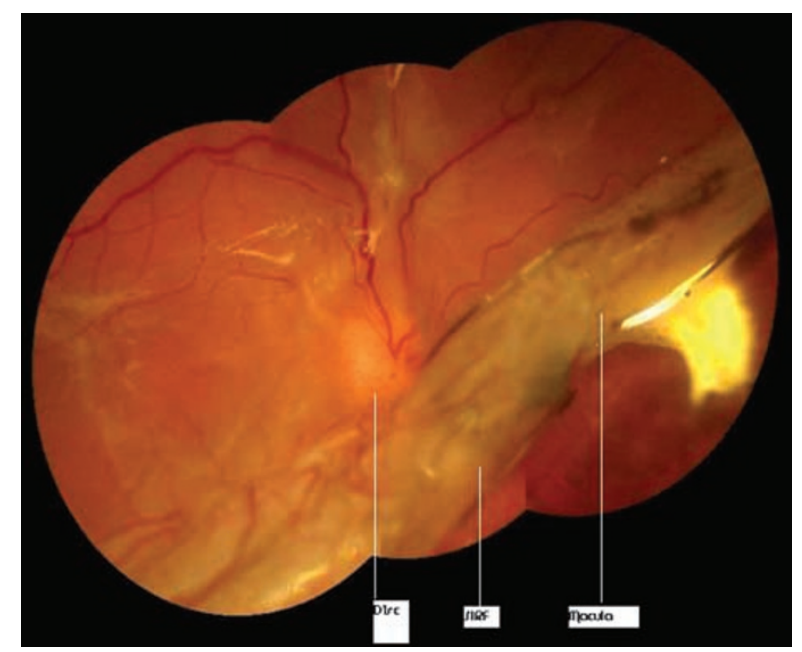

Figure 1 Severe retinal rolling (SIRF) involving macula in patient 2 .

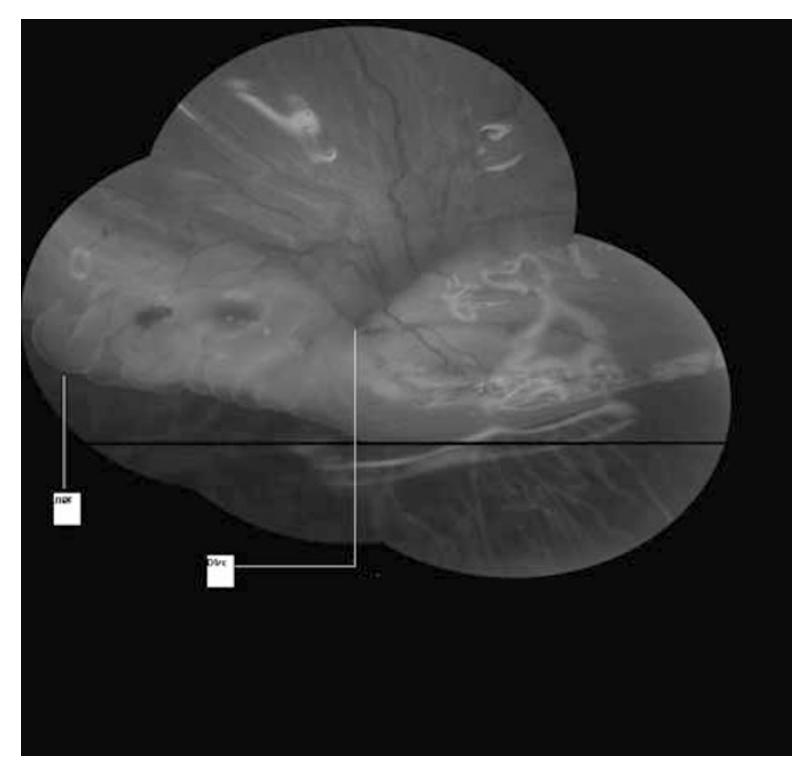

Figure 2 Retinal folding in concertina pattern (SIRF) in patient 4. trauma. There was a mean of 2.2 procedures before relaxing retinectomy was performed, range $1-3$. SIRF was noted from mean 4.2 months (range $2-6$ months) from the operation with the retinectomy. At the time of the last follow-up all patients continued to have a scrolled retinal edge involving the macula with silicone oil in situ (Figures 1 and 2). The superior retina remained attached in all patients but the vision remained poor at hand movements or perception of light. Peroperative complications such as haemorrhage are routinely recorded but were not seen in these cases. Nor were other predisposing factors, such as excessive postoperative inflammation or inadequate silicon oil fill, noted.

\section{Discussion}

SIRF occurred in $1.97 \%$ of patients undergoing relaxing retinectomy and silicone oil insertion. To our knowledge the complication has not been previously reported. Haut et $a l^{4}$ reported that $16 \%$ of 37 patients with relaxing retinectomies had epiretinal membranes at the posterior edge of the retinectomy, which was associated with some retinal rolling but the macula remained attached. Jacobs et $a l^{5}$ reported one case of nasal retinal rolling at the time of surgery. Possible mechanisms for the production of this complication could be persistent activation of PVR despite flattening of the retina in the early postoperative period. It was difficult to determine the exact location of the PVR membranes relative to the retinal surfaces. The possibilities are a single progressive fold, progressive rolling, or a concertina effect on membranes internally or externally. However, it is likely that each of the mechanisms is involved to a varying degree. Histological examination would be required to identify the configuration of membranes and folding.

In conclusion, SIRF is an uncommon but devastating complication of relaxing retinectomy. Surgeons should be aware of the possibility of this complication and its effects on visual outcome. 


\section{References}

1 Grigoropoulos VG, Benson S, Bunce C, Charteris DG. Functional outcome and prognostic factors in 304 eyes managed by retinectomy. Graefes Arch Clin Exp Ophthalmol 2007; 245(5): 641-649.

2 Quiram PA, Gonzales CR, Hu W, Gupta A, Yoshizumi MO, Kreiger AE et al. Outcomes of vitrectomy with inferior retinectomy in patients with recurrent rhegmatogenous retinal detachments and proliferative vitreoretinopathy. Ophthalmology 2006; 113(11): 2041-2047.
3 Blumenkranz MS, Azen SP, Aaberg T, Boone DC, Lewis H, Radtke $\mathrm{N}$ et al. Relaxing retinotomy with silicone oil or longacting gas in eyes with severe proliferative vitreoretinopathy. Silicone Study Report 5. The Silicone Study Group. Am J Ophthalmol 1993; 116: 557-564.

4 Haut J, Monin C, Larricart P, Van Effenterre G, Piaton JM, Flamand M. Study of a new series of large relaxing retinotomies. Ophthalmologica 1989; 198(1): 35-39.

5 Jacobs PM, Cooling RJ, Leaver PK, McLeod D. Retinal relieving incisions. Eye 1987; 1(Part 4): 500-503. 